\title{
Development and validation of an asthma knowledge questionnaire for use in Brazil***
}

\author{
Desenvolvimento e validação de um questionário de conhecimento \\ em asma para uso no Brasil
}

\author{
Marcos Carvalho Borges, Érica Ferraz, Sílvia Maria Romão Pontes, \\ Andrea de Cássia Vernier Antunes Cetlin, Roseane Durães Caldeira, \\ Cristiane Soncino da Silva, Ana Carla Sousa Araújo, Elcio Oliveira Vianna
}

\begin{abstract}
Objective: To develop and validate an asthma knowledge questionnaire for use in adult asthma patients in Brazil. Methods: A 34-item self-report questionnaire was constructed and administered to adult asthma patients and adult controls. The maximum total score was 34. Results: The questionnaire was shown to be discriminatory, with good reliability and reproducibility. The mean score for asthma patients and controls was, respectively, $21.47 \pm 4.11$ (range: 9-31) and $17.27 \pm 5.11$ (range: 7-28; $p<0.001$ ). The Kaiser-Meyer-Olkin measure of sampling adequacy was 0.53 , and the Bartlett's test of sphericity demonstrated a satisfactory suitability of the data to factor analysis $(p<0.001)$. There was no significant difference between the total scores obtained in the first and in the second application of the questionnaire within a two-week interval $(p=0.43)$. The internal consistency reliability (KR-20 coefficient) was 0.69. Conclusions: This study has validated an asthma knowledge questionnaire for use in Brazil.
\end{abstract}

Keywords: Asthma; Questionnaires; Validation studies; Reproducibility of results.

\section{Resumo}

Objetivo: Desenvolver e validar um questionário de conhecimento em asma para pacientes adultos asmáticos no Brasil. Métodos: Um questionário autoaplicável com 34 itens foi desenvolvido e aplicado em asmáticos e controles adultos. A pontuação total máxima era 34. Resultados: 0 questionário mostrou-se discriminante, com boa confiabilidade e reprodutibilidade. 0 escore médio para os asmáticos e controles foi, respectivamente, 21,47 \pm 4,11 (variação: 9-31) e 17,27 \pm 5,11 (variação: 7-28; $p<0,001$ ). 0 teste de Kaiser-Meyer-Olkin revelou uma medida de adequação de 0,53 , e o teste de esfericidade de Bartlett demonstrou uma adequação satisfatória dos dados para a análise fatorial ( $p<0,001)$. Não houve diferença significativa entre os escores totais obtidos na primeira e na segunda aplicação do questionário, com um intervalo de duas semanas $(p=0,43)$. 0 coeficiente de consistência interna (coeficiente KR-20) foi 0,69. Conclusões: Este estudo validou um questionário de educação em asma para uso no Brasil.

Descritores: Asma; Questionários; Estudos de validação; Reprodutibilidade dos testes.

\section{Introduction}

Asthma, a chronic inflammatory disease of the airways, is a serious public health problem throughout the world, affecting people of all ages and economic conditions. ${ }^{(1,2)}$ When uncontrolled, asthma can place severe limits on daily life and still lead to death. ${ }^{(3)}$ Despite advances in specific medications for asthma, the prevalence and the morbidity of uncontrolled asthma is still high. ${ }^{(4)}$
The treatment of asthma can be complex and requires the involvement of patients and their families. For the success in the treatment, patients with asthma should obtain specific knowledge about the disease, such as the pathophysiology of asthma, the purposes of the different types of medication, the management of environmental asthma triggers, the identification and manage-

\footnotetext{
* Study carried out in the Division of Pulmonology, Department of Internal Medicine, University of São Paulo at Ribeirão Preto School of Medicine, Ribeirão Preto, Brazil

Correspondence to: Elcio O. Vianna. Avenida Bandeirantes, 3900, CEP 14048-900, Ribeirão Preto, SP, Brasil.

Tel 5516 3602-2706. Fax 5516 3633-6695. E-mail: evianna@uol.com.br

Financial support: This study received financial support from the Fundação de Amparo à Pesquisa do Estado de São Paulo (FAPESP, Foundation for the Support of Research in the state of São Paulo).

Submitted: 19 June 2009. Accepted, after review: 11 September 2009.

** A versão completa em português deste artigo está disponível em www.jornaldepneumologia.com.br
} 
ment of asthma exacerbations, the use of inhalers, and the discrimination between controlled and uncontrolled asthma..$^{(1,5-7)}$ This knowledge could be acquired in medical visits with the patient care team and in education programs.

Education programs have improved the knowledge of asthma, the control of the disease, lung function parameters and treatment compliance, and they should be incorporated into patient care. ${ }^{(8,9)}$ The improvement of such knowledge is one of the main objectives of education programs, and its assessment is an important part of the intervention. ${ }^{(10)}$ Many asthma education programs use validated questionnaires to measure patient knowledge, the impact of the programs and the relationship between such knowledge and asthma control. $(10,11)$ Validated questionnaires are available in a number of languages, such as English, French and Spanish, but not in Portuguese. In addition, the knowledge of asthma differs among the various cultures and countries, and specific questionnaires and programs should therefore be developed to meet different needs. ${ }^{(11-14)}$

The objective of this study was to develop a reliable self-report asthma knowledge questionnaire that would be valid for use in adult asthma patients in Brazil.

\section{Methods}

This was a single-center study conducted at the University Hospital of the University of São Paulo Medical School at Ribeirão Preto, between July of 2008 and March of 2009, and approved by the Research Ethics Committee of the Hospital. All participating subjects gave written informed consent.

The questionnaire was applied to asthma patients and other subjects (controls) at the University Hospital. All asthma patients were screened by medical history, physical examination, routine laboratory tests and pulmonary function tests. These patients were diagnosed with asthma as defined in the Global Initiative for Asthma guidelines. ${ }^{(1)}$ The controls were individuals accompanying patients and had neither had asthma nor been involved in the care of a family member or friend with asthma.

We constructed a 34-item self-report questionnaire (available on the Brazilian Journal of Pulmonology website [http://www.jornaldepneumologia.com.br/english/artigo_detalhes. asp?id=1533 ) designed to explore aspects of asthma care and education program contents, such as etiology, pathophysiology, symptoms, triggers, treatment, use of inhalers, prevention and action plans. The response categories were "true", "false" or "not sure", the last being included to discourage guessing and scored as incorrect. ${ }^{(10)}$ The maximum total score was 34.

The steps used to determine the reliability and validity of the questionnaire were: content and face validity, test-retest reliability, construct and criterion-related validity and internal consistency.

There were no objective evaluations of content and face validity. ${ }^{(10)}$ All the questionnaire items were evaluated by a panel of nine respiratory physicians and three physical therapists with research interests, expertise in asthma management and involved in education programs for asthma patients. Experts from all regions of Brazil (southern, southeastern, central-west, northeastern, and northern) participated in the evaluation of the content and face validity. In addition, 10 volunteers with asthma evaluated the questionnaire regarding face and content, in order to identify ambiguities and lack of clarity.

The structure of the questionnaire was studied using principal component analysis and varimax rotation with Kaiser normalization. Since the questionnaire addressed several aspects, the results of the factor analysis would indicate whether it is appropriate to sum all of the items in a measurement or to treat factors as individual scales. ${ }^{(10)}$

Criterion-related validity was determined by comparing the responses to individual items and the total scores between asthma patients and controls. The Mann-Whitney test was used to evaluate the differences in total scores, and the chi-square test was used to compare the responses to individual items. Values of $p<0.05$ were considered significant.

The questionnaire was applied twice, within a two-week interval. To assess reliability, the Wilcoxon test was used to compare the total score of each application, and the McNemar's test was used to assess concordance in individual items.

The internal consistency of the items was evaluated using the Kuder-Richardson formula 20 (KR-20). Adequate values should be higher than 0.6. 
Statistical analyses were performed using the Statistical Package for the Social Sciences, version 15.0 (SPSS Inc., Chicago, IL, USA).

\section{Results}

During the study period, 134 asthma patients were enrolled in the study. The mean age of the asthma patients was $41 \pm 14$ years, and $99(74 \%)$ were female. We also included 33 control subjects (mean age: $37 \pm 13$ years), $16(48 \%)$ of whom were female.

Both the experts and the asthma patients considered the questionnaire to have an adequate content and face validity, and to cover the asthma concepts satisfactorily.
The sample size for the factor analysis was 33 items with one missing value, and a ratio of 3.94 respondents for each item was obtained. The Kaiser-Meyer-Olkin measure of sampling adequacy was 0.53 , considered adequate for the factor analysis, and the Bartlett's test of sphericity also demonstrated a satisfactory suitability of the data to factor analysis $(p<0.001)$. A loading cutoff of $>0.30$ was adopted, and 13 factors were extracted. Each factor explained $3.86-5.68 \%$ of the total variance, and $64.18 \%$ of the variance was explained by these 13 factors, revealing a weak factor structure. The pattern matrix of the loadings on the varimax rotated factors is presented in Table 1.

Table 1 - Factor analysis. ${ }^{\text {a }}$

\begin{tabular}{|c|c|c|c|}
\hline Cluster & Item & Loading & Contribution to the total variance \\
\hline \multirow[t]{2}{*}{1} & Item 30 - treatment & 0.774 & $5.68 \%$ \\
\hline & Item 28 - triggers & 0.615 & \\
\hline \multirow[t]{2}{*}{2} & Item 03 - etiopathology & -0.727 & $5.64 \%$ \\
\hline & Item 18 - triggers & 0.680 & \\
\hline \multirow[t]{3}{*}{3} & ltem 15 - treatment & 0.732 & $5.64 \%$ \\
\hline & Item 14 - inhalers & 0.662 & \\
\hline & Item 24 -triggers & 0.572 & \\
\hline \multirow[t]{4}{*}{4} & Item 08 - etiopathology & 0.668 & $5.55 \%$ \\
\hline & Item 06 - etiopathology & 0.651 & \\
\hline & Item 01 - etiopathology & 0.506 & \\
\hline & Item 19 - triggers & 0.378 & \\
\hline \multirow[t]{2}{*}{5} & Item 23 -triggers & 0.807 & $5.51 \%$ \\
\hline & Item 22 - triggers & 0.691 & \\
\hline \multirow[t]{3}{*}{6} & Item 04 - treatment & 0.689 & $5.34 \%$ \\
\hline & Item 32 - action plan & 0.588 & \\
\hline & ltem 21 - triggers & 0.507 & \\
\hline \multirow[t]{3}{*}{7} & Item 17 - treatment & 0.700 & $4.99 \%$ \\
\hline & Item 11 - treatment & 0.696 & \\
\hline & ltem 05 - treatment & 0.415 & \\
\hline \multirow[t]{3}{*}{8} & Item 07 - etiopathology & 0.784 & $4.59 \%$ \\
\hline & Item 33 - action plan & 0.485 & \\
\hline & Item 10 - treatment & 0.466 & \\
\hline \multirow[t]{2}{*}{9} & Item 13 - inhalers & 0.769 & $4.49 \%$ \\
\hline & Item 29 - action plan & 0.416 & \\
\hline \multirow[t]{3}{*}{10} & Item 25 - triggers & 0.836 & $4.49 \%$ \\
\hline & Item 09 - etiopathology & 0.584 & \\
\hline & ltem 16 - inhalers & 0.367 & \\
\hline \multirow[t]{2}{*}{11} & Item 27 - action plan & 0.849 & $4.27 \%$ \\
\hline & Item 31 - action plan & 0.511 & \\
\hline \multirow[t]{2}{*}{12} & Item 02 - etiopathology & 0.695 & $4.14 \%$ \\
\hline & Item 12 - treatment & 0.589 & \\
\hline \multirow[t]{2}{*}{13} & Item 26 - triggers & 0.708 & $3.86 \%$ \\
\hline & Item 34 - action plan & 0.431 & \\
\hline
\end{tabular}

${ }^{a}$ The factor analysis did not reveal a strong cluster structure, suggesting that the questionnaire should be interpreted as a one-dimensional element by the sum of all items, rather than as a multidimensional instrument. 
The mean questionnaire score was $21.47 \pm 4.11$ (range: 9-31) for asthma patients, and 17.27 \pm 5.11 (range: 7-28) for controls $(p<0.001)$. The differences in responses between asthma patients and controls for individual items are shown in Table 2. At the first and second application, the mean questionnaire score was, respectively, $22.13 \pm 4.32$ (range: 13-31) and $21.77 \pm 3.91$ (range: 13-29), with no significant difference between the total scores obtained within the two-week interval $(p=0.43)$. When analyzed separately, all items were also considered to be concordant ( $p>0.21)$.
The internal consistency reliability (KR-20 coefficient) of the questionnaire was 0.69 .

\section{Discussion}

We developed and validated a questionnaire to assess the asthma knowledge of adults with asthma, especially for use in developing countries where Portuguese is spoken. This 34-item questionnaire was carefully constructed to measure asthma knowledge and was proven to be valid, reliable, sensitive, simple to administer,

Table 2 - Comparison of incorrect responses per item to the 34-item asthma knowledge questionnaire between asthma patients and controls. ${ }^{2}$

\begin{tabular}{|c|c|c|c|}
\hline Item & Asthma patients, n (\%) & Controls, n (\%) & $\mathrm{p}$ \\
\hline 1 & $26(19)$ & $11(33)$ & 0.08 \\
\hline 2 & $43(32)$ & $12(36)$ & 0.64 \\
\hline 3 & $99(74)$ & $26(79)$ & 0.56 \\
\hline 4 & $43(32)$ & $18(55)$ & 0.02 \\
\hline 5 & $91(68)$ & $26(79)$ & 0.22 \\
\hline 6 & $102(76)$ & $28(85)$ & 0.28 \\
\hline 7 & $59(44)$ & $22(67)$ & 0.02 \\
\hline 8 & $74(55)$ & $17(52)$ & 0.70 \\
\hline 9 & $26(19)$ & $12(36)$ & 0.04 \\
\hline 10 & $94(70)$ & $25(76)$ & 0.52 \\
\hline 11 & $55(41)$ & $22(67)$ & 0.008 \\
\hline 12 & $128(96)$ & 32 (97) & 1.00 \\
\hline 13 & $94(70)$ & $28(85)$ & 0.09 \\
\hline 14 & $20(15)$ & $13(39)$ & 0.002 \\
\hline 15 & $7(5)$ & $7(21)$ & 0.008 \\
\hline 16 & $83(62)$ & $29(88)$ & 0.005 \\
\hline 17 & $84(63)$ & 26 (79) & 0.08 \\
\hline 18 & $9(7)$ & $6(18)$ & 0.08 \\
\hline 19 & $56(42)$ & $14(42)$ & 0.95 \\
\hline 20 & 0 & $2(6)$ & 0.04 \\
\hline 21 & $3(2)$ & $2(6)$ & 0.26 \\
\hline 22 & 26 (19) & $16(49)$ & 0.001 \\
\hline 23 & $38(28)$ & 11 (33) & 0.57 \\
\hline 24 & $21(16)$ & 13 (39) & 0.002 \\
\hline 25 & $38(28)$ & $12(36)$ & 0.37 \\
\hline 26 & 89 (66) & 27 (82) & 0.09 \\
\hline 27 & 27 (20) & $9(27)$ & 0.37 \\
\hline 28 & $30(22)$ & $10(30)$ & 0.34 \\
\hline 29 & $56(42)$ & $15(46)$ & 0.70 \\
\hline 30 & $19(14)$ & 12 (36) & 0.003 \\
\hline 31 & $11(8)$ & $5(15)$ & 0.32 \\
\hline 32 & $64(48)$ & $14(42)$ & 0.58 \\
\hline 33 & 32 (24) & $16(49)$ & 0.005 \\
\hline 34 & $32(24)$ & $14(42)$ & 0.03 \\
\hline
\end{tabular}

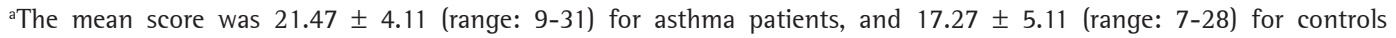
$(\mathrm{p}<0.001)$. 
appropriate and intelligible to the target population, similar to questionnaires validated for use in other countries. ${ }^{(10,11,15)}$

The questionnaire meets the criterion of content/face validity. For construct validity, the desirable ratio of respondents varies from 4 to 10 subjects per item, with a minimum number of 100 subjects. ${ }^{(16,17)}$ We obtained a ratio of 3.94 respondents for each question, which might be a limitation for the factor analysis. The factor analysis did not reveal a strong cluster structure, suggesting that the questionnaire should be interpreted as a one-dimensional element by the sum of all items, rather than as a multidimensional instrument.

By comparing the total scores and the individual items, we also demonstrated that the questionnaire clearly distinguished between asthma patients and controls, having temporal stability and acceptable internal consistency. The asthma patients answered correctly only $63 \%$ of the questions. The questions that were answered incorrectly, for the majority of the asthma patients, were mainly those that were about asthma treatment. In addition, 96\% of the asthma patients considered bronchodilators to be the best medication to control asthma; 63\% believed that inhaled corticosteroids should not be used for asthma; and 70\% thought that they could become addicted to inhaled medications. These issues should be considered in medical visits and education programs. Although there is not an expected threshold for the asthma patients, and considering the importance of the knowledge in asthma treatment, we considered the knowledge of these patients in our hospital to be insufficient. Practical actions to improve asthma knowledge, such as education programs, should be considered. Since only adults were enrolled, further studies are needed in order to validate this questionnaire for use in children and adolescents with asthma, as well as in their families and guardians.

There were some limitations in this study. Although the questionnaire was suitable for the factor analysis, we had only a ratio of 3.94 respondents for each question, and the questionnaire did not show a strong cluster structure. When the items were analyzed separately, 13 questions could significantly differentiate asthma patients from controls, 5 questions showed a tendency towards significance, and
16 did not reach statistically significant differences between asthma patients and controls. Therefore, the questionnaire should be interpreted with the sum of all items rather than as isolated items or clusters of questions.

Although a number of asthma knowledge questionnaires have been developed, this was the first study to construct a specific questionnaire in Portuguese. Obviously, we could have translated an existing questionnaire. However, translating a questionnaire is difficult, and such a translation might not be suitable for all populations, since medical terminology and practices, as well as knowledge about asthma, differ among populations. ${ }^{(11-14)}$

Brazil is a large country with five distinct regions (southern, southeastern, central-west, northeastern, and northern), each with distinct habits and cultures. In order to avoid regional biases, experts from all regions were consulted so that the questionnaire would be suitable for all patients in Brazil. Considering some cultural similarities between Brazil and other developing countries, our questionnaire could also be useful in other countries where Portuguese is spoken.

In conclusion, our 34-item questionnaire is a valid and reliable instrument for measuring asthma knowledge in adults with asthma in developing countries where Portuguese is spoken.

\section{Acknowledgments}

The following investigators and institutions participated in this study: Álvaro Augusto Souza da Cruz Filho (Federal University of Bahia); Ana Luisa Godoy Fernandes (Federal University of São Paulo); Carlos Cezar Fritscher (Pontifical Catholic University of Rio Grande do Sul); Fabíola Reis de Oliveira (University of São Paulo); Heicilainy Del Carlos Gondim (General Hospital of Goiânia Alberto Rassi); Luiz Carlos Corrêa da Silva (Federal University of Rio Grande do Sul); Márcia Alcântara Holanda (Federal University of Ceará); Maria Alenita de Oliveira (Federal University of São Paulo); Maria do Rosário da Silva Ramos Costa (Federal University of Maranhão); Maria do Socorro de Lucena Cardoso (Federal University of Amazonas); Rafael Stelmach (University of São Paulo); Sonia Regina Pasian (University of São Paulo); and Willy Sarti (University of São Paulo). 


\section{References}

1. Global Initiative for Asthma. Global Strategy for Asthma Management and Prevention. Bethesda: National Institutes of Health, National Heart, Lung, and Blood Institute; 2007.

2. IV Brazilian Guidelines for the management of asthma [Article in Portuguese]. J Bras Pneumol. 2006;32 Suppl 7:S447-74.

3. Robertson CF, Rubinfeld AR, Bowes G. Deaths from asthma in Victoria: a 12-month survey. Med J Aust. 1990;152(10):511-7.

4. Peters SP, Ferguson G, Deniz Y, Reisner C. Uncontrolled asthma: a review of the prevalence, disease burden and options for treatment. Respir Med. 2006;100(7):1139-51.

5. Schaffer SD, Yarandi HN. Measuring asthma selfmanagement knowledge in adults. J Am Acad Nurse Pract. 2007;19(10):530-5.

6. 1 Consenso Brasileiro de Educação em Asma. J Pneumol. 1996;22(Suppl 1):1-25.

7. Evans D. To help patients control asthma the clinician must be a good listener and teacher. Thorax. 1993;48(7):685-7.

8. Guevara JP, Wolf FM, Grum CM, Clark NM. Effects of educational interventions for self management of asthma in children and adolescents: systematic review and meta-analysis. BMJ. 2003;326(7402):1308-9.

9. Lahdensuo A, Haahtela T, Herrala J, Kava T, Kiviranta $\mathrm{K}$, et al. Randomised comparison of guided self management and traditional treatment of asthma over one year. BMJ. 1996;312(7033):748-52.

10. Allen RM, Jones MP. The validity and reliability of an asthma knowledge questionnaire used in the evaluation of a group asthma education self-management program for adults with asthma. J Asthma. 1998;35(7):537-45.

11. Báez Saldaña AR, Chapela Mendoza R, Herrera Kiengelher L, Ortiz Siordia R, Salas Hernández J. Development of a questionnaire to measure asthmatic patients' knowledge of their disease [Article in Spanish]. Arch Bronconeumol. 2007;43(5):248-55.

12. Bailey EJ, Cates CJ, Kruske SG, Morris PS, Brown N, Chang AB. Culture-specific programs for children and adults from minority groups who have asthma. Cochrane Database Syst Rev. 2009;(2):CD006580.

13. Lee AC, Brugge D, Phan L, Woodin M. A Comparison of knowledge about asthma between Asians and non-Asians at two pediatric clinics. J Immigr Minor Health. 2007;9(4):245-54.

14. Malone AM, Gupta RS, Lyttle CS, Weiss KB. Characterizing community-based asthma knowledge in Chicago and its high risk neighborhoods. J Asthma. 2008;45(4):313-8.

15. Stone DH. Design a questionnaire. BMJ. 1993;307(6914):1264-6.

16. de Vet HC, Adèr HJ, Terwee CB, Pouwer F. Are factor analytical techniques used appropriately in the validation of health status questionnaires? A systematic review on the quality of factor analysis of the SF-36. Qual Life Res. 2005;14(5):1203-18; discussion 1219-21, 1223-4.

17. Kline P. The Handbook of Psychological Testing. London: Routledge; 1993.

\section{About the authors}

\section{Marcos Carvalho Borges}

Visiting Professor. Department of Internal Medicine, University of São Paulo at Ribeirão Preto School of Medicine, Ribeirão Preto, Brazil.

\section{Érica Ferraz,}

Physical Therapist. University of São Paulo at Ribeirão Preto School of Medicine, Ribeirão Preto, Brazil.

\section{Sílvia Maria Romão Pontes}

Physician. University of São Paulo at Ribeirão Preto School of Medicine, Ribeirão Preto, Brazil.

\section{Andrea de Cássia Vernier Antunes Cetlin}

Physician. University of São Paulo at Ribeirão Preto School of Medicine, Ribeirão Preto, Brazil.

\section{Roseane Durães Caldeira}

Physical Therapist. University of São Paulo at Ribeirão Preto School of Medicine, Ribeirão Preto, Brazil.

\section{Cristiane Soncino da Silva}

Physical Therapist. University of São Paulo at Ribeirão Preto School of Medicine, Ribeirão Preto, Brazil.

\section{Ana Carla Sousa Araújo}

Physician. University of São Paulo at Ribeirão Preto School of Medicine, Ribeirão Preto, Brazil.

\section{Elcio Oliveira Vianna}

Associate Professor. Department of Internal Medicine, University of São Paulo at Ribeirão Preto School of Medicine, Ribeirão Preto, Brazil. 